\title{
Korean reference for full-term birth length by sex: data from the 4th Korean National Health and Nutrition Examination Survey (KNHANES-IV; 2007- 2009)
}

\author{
Ji Hyun Kim, MD, PhD', \\ Jun $A h$ Lee, $M D, P^{2}{ }^{2}$, \\ Dong Ho Kim, MD', \\ Jung Sub Lim, MD, PhD ${ }^{3}$ \\ 'Department of Pediatrics, Dongguk \\ University Ilsan Hospital, Goyang, \\ Korea \\ ${ }^{2}$ Center of Pediatric Oncology, National \\ Cancer Center, Goyang, Korea \\ ${ }^{3}$ Department of Pediatrics, Korea \\ Cancer Center Hospital, Seoul, Korea
}

Purpose: The purpose of this study was to construct reference data for birth length of full-term and preterm Korean infants by sex and to define a sex-specific birth length cut-off to identify small for gestational age (SGA).

Methods: Data were collected from the 4th Korean National Health and Nutrition Examination Survey (2007-2009), comprising 843 children with birth length data and birth history.

Results: References for the 3rd, 10th, 25th, 50th, 75th, 90th, and 97th percentiles of birth length and weight were created using singleton neonates of gestational age (GA) 36-37 weeks and 38-41 weeks by sex. The birth length cutoff value for SGA ( $<10$ th percentile) was $48 \mathrm{~cm}$ in both male and female neonates, and the $\leq 3 \mathrm{rd}$ percentile cutoff was $47 \mathrm{~cm}$ in males and $46 \mathrm{~cm}$ in females born at a GA of 38-41 weeks.

Conclusion: New Korean reference data were created for birth length and differed from those of other ethnicities. Further research on short-term and long-term health outcomes of SGA infants based on the new reference data is needed.

Keywords: Birth length, Gestational age, Reference, Small for gestational age infant, Koreans

\section{Introduction}

The term small for gestational age (SGA) is used to describe a neonate who is smaller than average after adjusting for sex and gestational age (GA). SGA infants usually have a birth weight below the 10th percentile for GA. ${ }^{1)}$ Some infants born SGA, particularly due to intrauterine growth restriction (IUGR), suffer acute and chronic consequences. In the neonatal period, some suffer from perinatal events, such as hypoglycemia, gastro-esophageal reflux, and hypothermia. ${ }^{2}$ Such individuals can be and remain short in stature or suffer premature adrenarche and polycystic ovarian syndrome. ${ }^{3,4)}$ Furthermore, SGA individuals demonstrate significantly increased risks for obesity, hypertension, dyslipidemia, insulin resistance, type 2 diabetes mellitus, and cardiovascular diseases (CVD) from childhood to adulthood. ${ }^{2}$ For proper assessment and management of SGA individuals, up-to-date, ethnicity-specific birth length or birth weight references according to GA are needed. ${ }^{5}$ Many countries, including the United States, have reported new birth weight or birth length references by sex and GA, as the old references no longer fit the contemporary population. ${ }^{6-11)}$ The new references and cutoffs can be used to identify children at risk for short adult stature and future metabolic disease. Previously, we reported Korean birth weight references according to GA and sex. ${ }^{12)}$ However, birth length references based on the Korean population remained absent at the time of this

Address for correspondence:

Jung Sub Lim, MD, PhD

Department of Pediatrics, Korea Cancer Center Hospital, 75 Nowonro, Nowon-gu, Seoul 01812, Korea

Tel: +82-2-970-1224

Fax: $+82-2-970-8921$

E-mail: limjs@kcch.re.kr https://orcid.org/0000-0001-95608921 
study. Thus, the objectives of this study were as follows: (1) to create sex-specific birth length reference data for Koreans; (2) to create a sex-specific birth length cutoff to define SGA; and (3) to compare Korean-specific birth length reference data and cutoffs to those of other countries.

\section{Materials and methods}

\section{Study subjects}

This study was performed using data from the 4 th Korean National Health and Nutrition Examination Survey (KNHANES-IV; 2007-2009), a cross-sectional and nationally representative survey with a multistage and stratified sampling design conducted by the Division of Chronic Disease Surveillance of the Korea Centers for Disease Control and Prevention. Written informed consent was secured from the respective caretakers of all participants before the study began, and the KNHANES-IV was conducted following ethical approval by the Institutional Review Board of Korea Centers for Disease Control and Prevention (No: 2007-02-04-P, 2008-04EXP-01-C, 2009-01CON-03-2C). In the KNHANES$\mathrm{IV}$, the birth weight and birth length of children $1-3$ years of age ( $n=895$, representing 42,756 subjects) were available. Those without birth length were excluded $(n=52)$. Thus, the final analytical sample consisted of 843 subjects (male, 459; female, 384).

\section{Reference birth weights and lengths for 36-37 week and 38- to 41-week gestational ages}

In the KNHANES-IV, GA was identified using the closedended question "Was your baby born between the expected birth date \pm 2 weeks?" If the answer was yes, the baby was defined as full-term (38-41 weeks). When the birth date was between 2-4 weeks earlier than expected, the baby was designated as GA 36-37 weeks. For reference, a GA of 38 weeks represented 38 weeks $+0-6$ days. Multiple births $(n=10)$ were excluded, as the negative impact on intrauterine growth is well known. Thus, we used data of singleton newborns. We further excluded "extreme outliers," which were defined as value $>2$ times the interquartile range (25th to 75 th percentiles) above the third quartile for each GA. ${ }^{13)}$ There were 6 extreme outliers based on the birth length and 3 based on birth weight. Those with a GA below $36(n=6)$ or an unspecified GA $(\mathrm{n}=18)$ were also excluded. Thus, data of 67 (39 males) singleton newborns with GA of 36-37 weeks and data of 736 (399 males) with GA of 38-41 weeks were used for reference. The 3rd, 10th, 25th, 50th, 75th, 90th, and 97th percentiles for male and female birth lengths were calculated.

\section{Small for gestational age definition}

We used 2 identifiers to define SGA: a birth weight below the 10th percentile (SGAW) and a birth length below the 10th percentile (SGAL). ${ }^{1,6)}$

\section{Statistical analysis}

All statistical analyses were performed using SPSS ver. 17.0 (SPSS Inc., Chicago, IL, USA). The $P$-values of $<0.05$ were considered significant. The data are presented as the mean \pm standard deviation concerning the percentile values for birth weight and length according to GA of 36-37 weeks and of 38-41 weeks.

\section{Results}

\section{Subject characteristics}

The characteristics of the study subjects are presented in Table 1. The 843 subjects in this study were born between 2005 and 2009 in Korea. The mean birth length was $50.7 \pm 2.9 \mathrm{~cm}$, and the mean birth weight was $3,283 \pm 438 \mathrm{~g}$. Female infants had lower birth lengths and birth weights than male infants $(50.2 \pm 3.2 \mathrm{~cm}$ vs. $51.1 \pm 2.7 \mathrm{~cm}, 3,225 \pm 464 \mathrm{~g}$ vs. $3,327 \pm 413 \mathrm{~g}$, respectively; $P<0.001$ ). There was no difference in birth weight concerning vaginal delivery and caesarean section. However, the birth lengths of infants born by caesarean section were shorter those born by vaginal delivery $(50.4 \pm 3.4 \mathrm{~cm}$ vs. $50.9 \pm 2.6 \mathrm{~cm}$, respectively; $P=0.046$ ). Full-term neonates comprised $91.3 \%$ of the participants $(\mathrm{n}=770)$, and preterm neonates younger than 37

Table 1. The characteristics of the study subjects

\begin{tabular}{|c|c|c|c|c|c|}
\hline Variable & No. $(\%)$ & Birth weight (g) & $P$-value & Birth length (cm) & $P$-value \\
\hline Total & 843 & $3,283 \pm 438$ & & $50.7 \pm 2.9$ & \\
\hline \multicolumn{6}{|l|}{ Sex } \\
\hline Male & $459(54.4)$ & $3,327 \pm 413$ & $<0.001$ & $51.1 \pm 2.7$ & $<0.001$ \\
\hline Female & $384(45.6)$ & $3,225 \pm 464$ & & $50.2 \pm 3.2$ & \\
\hline \multicolumn{6}{|l|}{ Multiplicity } \\
\hline Singleton & $833(98.8)$ & $3,289 \pm 436$ & 0.001 & $50.8 \pm 2.9$ & 0.002 \\
\hline Twin+ & $10(1.2)$ & $2,855 \pm 349$ & & $47.9 \pm 2.1$ & \\
\hline \multicolumn{6}{|l|}{ Delivery type } \\
\hline Vaginal & $522(61.9)$ & $3,295 \pm 403$ & 0.333 & $50.9 \pm 2.6$ & 0.046 \\
\hline Caesarean section & $321(38.1)$ & $3,264 \pm 491$ & & $50.4 \pm 3.4$ & \\
\hline
\end{tabular}

Values are presented as mean \pm standard deviation unless otherwise indicated. 
weeks made up $8.7 \%(n=73)$.

\section{Percentile distributions of birth length and birth weight by sex}

The mean and percentiles of birth length and weight according to GA of males are presented in Table 2, and the corresponding female data are presented in Table 3 . In creating the percentiles, outliers and twins were excluded; therefore, data from 736 (399 males) singleton infants born between 38-41 weeks and from 67 infants born between 36-37 weeks were used. At full-term, the 10th percentile birth length was $48 \mathrm{~cm}$ in both males and females, the 10th percentile birth weight was 2,900 $\mathrm{g}$ for males and 2,828 $\mathrm{g}$ for females, and the $3 \mathrm{rd}$ percentile birth length was $47 \mathrm{~cm}$ for males and $46 \mathrm{~cm}$ for females.

\section{Prevalence of SGA}

The prevalence (\%) of SGA in full-term neonates when using the 10th percentile as the cutoff point for either birth length or weight is shown in Fig. 1. In full-term neonates, a total of 745 subjects (including outliers) were divided based on birth length and weight. Of the subjects, $86.3 \%(n=643)$ possessed a greater than 10th percentile value for both birth length and weight (group I). The others fell into 3 groups: $3.9 \%(n=29)$ were of normal length and low weight (group II); $7.0 \%(n=52)$ were short and of normal weight (group III); and 2.8\% $(n=21)$ were short and of low weight (group IV). Considering SGA based only on birth weight, short newborn infants of normal weight (group III) were neglected from all SGA classifications, consisting of $51 \%$ of all individuals.

\section{Discussion}

In this study, we introduced references for Korean birth length and weight based on the nation-wide survey data from

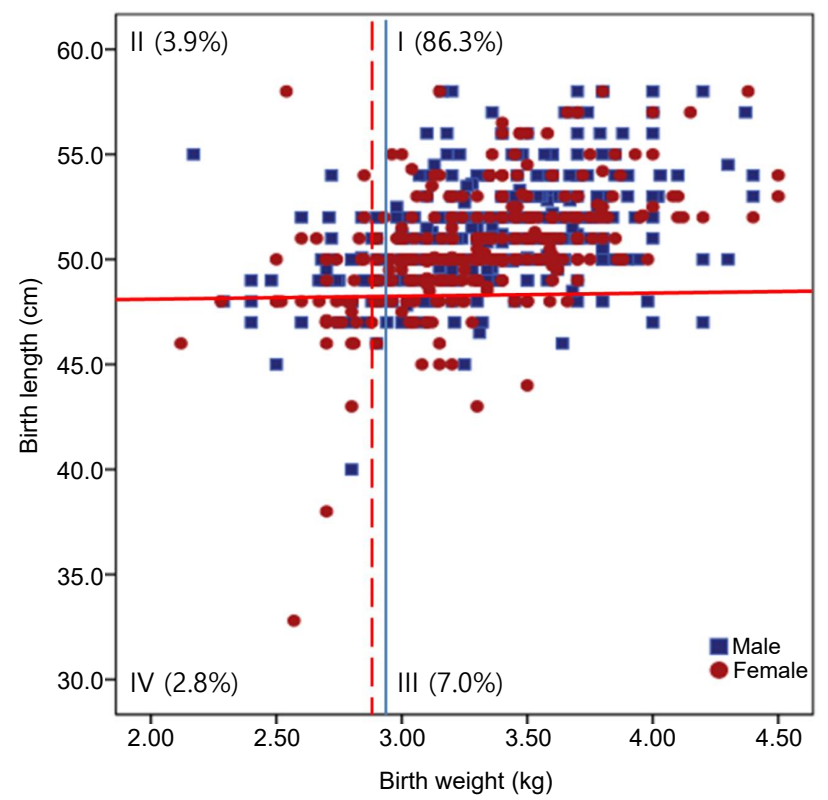

Fig. 1. The birth weight and length of full-term infants by sex. The horizontal red line reflects 10th percentile for birth length in both sexes. The vertical line reflects 10th percentile for birth weight (male; full line). By these line full-term infants are divided by 4 groups: group I; normal birth length and weight, group II; normal length and low weight, group III; short and of normal weight, group IV; short and of a low weight.

Table 2. Mean and percentiles of the birth length and weight of male Korean neonates ( $n=440$ )

\begin{tabular}{|c|c|c|c|c|c|c|c|c|c|c|}
\hline & \multirow{2}{*}{ GA* week } & \multirow{2}{*}{ No. } & \multirow{2}{*}{ Mean \pm SD } & \multicolumn{7}{|c|}{ Percentiles } \\
\hline & & & & $3 r d$ & 10th & 25th & 50th & 75th & 90th & 97th \\
\hline \multirow[t]{3}{*}{ Length $(\mathrm{cm})$} & $38-41$ & 399 & $51.2 \pm 2.4$ & 47.0 & 48.0 & 50.0 & 51.0 & 52.2 & 54.0 & 57.0 \\
\hline & $36-37$ & 39 & $50.4 \pm 2.5$ & 44.2 & 47.0 & 49.0 & 50.5 & 52.0 & 53.0 & 56.4 \\
\hline & $<35$ & 2 & $46.5 \pm 2.1$ & - & - & - & - & - & - & - \\
\hline \multirow[t]{3}{*}{ Weight (g) } & $38-41$ & 399 & $3,358 \pm 367$ & 2,693 & 2,900 & 3,120 & 3,360 & 3,600 & 3,800 & 4,020 \\
\hline & $36-37$ & 39 & $3,225 \pm 438$ & 2,435 & 2,780 & 2,900 & 3,200 & 3,460 & 3,780 & 4,275 \\
\hline & $<35$ & 2 & $2,420 \pm 113$ & - & - & - & - & - & - & - \\
\hline
\end{tabular}

$\mathrm{SD}$, standard deviation.

*GA: gestational age; 36 weeks represents 36 weeks + 0-6 days.

Table 3. Mean and percentiles of the birth length and weight of female Korean neonates $(n=369)$

\begin{tabular}{|c|c|c|c|c|c|c|c|c|c|c|}
\hline & \multirow{2}{*}{$G A^{*}$ week } & \multirow{2}{*}{ No. } & \multirow{2}{*}{ Mean $\pm S D$} & \multicolumn{7}{|c|}{ Percentiles } \\
\hline & & & & $3 r d$ & 10th & 25th & 50th & 75th & 90th & 97th \\
\hline \multirow[t]{3}{*}{ Length $(\mathrm{cm})$} & $38-41$ & 337 & $50.5 \pm 2.8$ & 46.0 & 48.0 & 49.0 & 50.0 & 52.0 & 54.0 & 56.4 \\
\hline & $36-37$ & 28 & $49.0 \pm 2.6$ & 43.0 & 45.0 & 47.4 & 49.0 & 50.6 & 52.0 & 53.7 \\
\hline & $<35$ & 4 & $40.6 \pm 7.5$ & - & - & - & - & - & - & - \\
\hline \multirow[t]{3}{*}{ Weight (g) } & $38-41$ & 337 & $3,293 \pm 374$ & 2,612 & 2,828 & 3,040 & 3,280 & 3,535 & 3,752 & 4,064 \\
\hline & $36-37$ & 28 & $2,899 \pm 468$ & 1,930 & 2,140 & 2,548 & 2,960 & 3,230 & 3,506 & 3,620 \\
\hline & $<35$ & 4 & $1,673 \pm 1.007$ & - & - & - & - & - & - & - \\
\hline
\end{tabular}

SD, standard deviation.

*GA: gestatioal age; 36 weeks represents 36 weeks + 0-6 days. 
the KNHANES-IV. This new Korean birth length data may be useful in assessing long-term health risks, such as short stature in childhood and metabolic risk in adulthood for children born with SGA. Furthermore, we showed that approximately half of infants classified as SGA, who are short but have a normal birth weight, might be misclassified as appropriate gestational age (AGA); this supports the need for updates and Korean-specific reference curves for birth length.

Contemporary ethnicity-specific birth weight references are needed to identify SGA neonates who might suffer from acute and chronic consequences. ${ }^{5)}$ Some SGA neonates are born following IUGR, and the suboptimal fetal growth occurring in IUGR fetuses is an important cause of perinatal mortality and morbidity. ${ }^{2)}$ Furthermore, SGA children have demonstrated significantly increased risks for obesity, hypertension, dyslipidemia, insulin resistance, type 2 diabetes mellitus, and cerebrovascular disease from childhood to adulthood., ${ }^{2,14}$ Furthermore, approximately $13 \%$ of children born with SGA remain short-statured and constitute a significant proportion of adults with short stature. ${ }^{15)}$ In a Swedish birth cohort, SGA infants demonstrated a 7 -fold higher risk of short stature in adulthood compared to non-SGA infants. ${ }^{4)}$ They also revealed that the majority $(61.7 \%)$ of the short newborn population may be misclassified as AGA if classified only in terms of birth weight. Furthermore, a slightly higher relative risk of short stature was obtained using birth length rather than birth weight to define SGA. ${ }^{16,17)}$ Additionally, the postnatal growth patterns were similar in SGAL and SGAW. In our study, when SGA was defined only by birth weight, $71.2 \%$ of short newborns were classified as AGA

Growth hormone $(\mathrm{GH})$ treatment for SGA children is standard practice. Many studies have shown that adult height is increased by GH therapy in these children. ${ }^{18,19)}$ Short-term GH treatment reduces body fat while promoting lean body mass and may reduce cardio-metabolic risk in SGA children. ${ }^{20)}$ Furthermore, a study from Sweden reported that GH therapy showed a significant and cost-effective improvement in health and quality of life. ${ }^{21)}$ Thus, the U.S. Food and Drug Administration and the European Medicines Agency have approved GH treatment for children with short stature who are born SGA. In Korea, medical insurance benefits have been applied to GH treatment for SGA children since 2014. Therefore, it is important to define SGA not only to reduce perinatal morbidity, but also to manage short stature in children and adolescents.

Moreover, it is well known that there are racial and ethnic differences in birth weight and birth length. ${ }^{22-24)}$ Furthermore, significant interactions have been found between race and maternal variables, especially after beginning antenatal care. Thus, ethnicity- and sex-specific references for birth weight and birth length are important. As the KNHANES-IV data did not show the specific GA, we first compared the birth weight reference of this study with that in our previous work concerning Korean birth weight. The values for the 10th, 50th, and 90th percentiles of this study for full-term (GA of 38-41 weeks) were between a GA of 39 weeks and a GA of 40 weeks in previous studies concerning both sexes. ${ }^{25)}$

Compared to the new USA intrauterine growth data of a GA of 39 weeks and a GA of 40 weeks, ${ }^{6}$ our references for full-term birth length values were similar to the USA data for a GA of 40 weeks. The $3 \mathrm{rd}, 10 \mathrm{th}, 25 \mathrm{th}, 50 \mathrm{th}, 75 \mathrm{th}, 90 \mathrm{th}$, and 97 th percentiles for birth length at a GA of 40 weeks were 46.9, 48.4, 49.9, 51.6, $53.2,54.7$, and $56.1 \mathrm{~cm}$, respectively, in male neonates and 46.1, $47.6,49.1,50.8,52.4,53.8$, and $55.1 \mathrm{~cm}$ in female neonates. Compared to the new Japanese neonatal anthropometric charts for $\mathrm{GA},{ }^{11)}$ our reference values for the full term were higher than the former. The 3rd, 10th, 50th, 90th, and 97th percentiles for the birth length of a GA of 40 weeks were 45.9, 47.1, 49.4, 51.7 , and $52.7 \mathrm{~cm}$, respectively, in both sexes. These variations can mainly be attributed to ethnic differences, which were previously discussed in a study of the Korean reference for birth weight. ${ }^{12)}$ The other reason for these differences is that the new Japanese charts were based on data from subjects born only via vaginal delivery. Compared to other countries' GA of 40 weeks, the Korean birth length was similar to that of Turkey and Israel and higher than that of Indonesia. ${ }^{26-28)}$

There were some limitations in the present study. First, the most important limitation of the provided reference is that, like other population-based studies, it is cross-sectional in nature rather than comprised of longitudinal measurements. ${ }^{5,29)}$ Second, there was a small number of subjects in the KNHANESIV, and the specific GA per subject was lacking, which invalidated the study's ability to create a reference concerning length for GA. Third, it was not easy to distinguish the infant of a multicultural family, but their portion is not higher than the present, so the effect on the result was considered insignificant. Thus, further research, including greater numbers of subjects with specified GAs, is needed concerning Koreans.

In conclusion, we calculated the means and percentiles for birth length in Korean neonates based on data from the KNHANES-IV. We created new reference curves using the 10th percentile as the cutoff point for birth length and weight in Korean neonates. We also created a new cutoff for SGA by birth length. As some SGA neonates experienced short-term and long-term health risks, these data and curves provide useful information for not only Korean endocrinologists, but also for other specialists, including neonatologists, for planning research or targeting prevention of metabolic diseases, such as obesity, diabetes, and CVD.

\section{Conflict of interest}

No potential conflict of interest relevant to this article was reported.

\section{Ethical statement}

The Research Ethics Committee of the Korea Center for Disease Control approved the study protocol (No:2007-02-04-P, 2008-04EXP-01-C, 2009-01CON-03-2C), and all participants or their parents signed a written informed consent form. 


\section{References}

1. Wa C. Prematurity and intrauterine growth restriction. 19th ed. Philadelphia (PA): Elsevier Saunders, 2011.

2. Chernausek SD. Update: consequences of abnormal fetal growth. J Clin Endocrinol Metab 2012;97:689-95.

3. Itabashi K, Mishina J, Tada H, Sakurai M, Nanri Y, Hirohata Y. Longitudinal follow-up of height up to five years of age in infants born preterm small for gestational age; comparison to full-term small for gestational age infants. Early Hum Dev 2007;83:327-33.

4. Karlberg J, Albertsson-Wikland K. Growth in full-term small-for-gestational-age infants: from birth to final height. Pediatr Res 1995;38:733-9.

5. Goldenberg RL, Cutter GR, Hoffman HJ, Foster JM, Nelson KG, Hauth JC. Intrauterine growth retardation: standards for diagnosis. Am J Obstet Gynecol 1989;161:271-7.

6. Olsen IE, Groveman SA, Lawson ML, Clark RH, Zemel BS. New intrauterine growth curves based on United States data. Pediatrics 2010;125:e214-24.

7. Cole TJ, Williams AF, Wright CM; RCPCH Growth Chart Expert Group. Revised birth centiles for weight, length and head circumference in the UK-WHO growth charts. Ann Hum Biol 2011;38:7-11.

8. Salihoglu O, Karatekin G, Uslu S, Can E, Baksu B, Nuhoglu A. New intrauterine growth percentiles: a hospital-based study in Istanbul, Turkey. J Pak Med Assoc 2012;62:1070-4.

9. Sankilampi U, Hannila ML, Saari A, Gissler M, Dunkel L. New population-based references for birth weight, length, and head circumference in singletons and twins from 23 to 43 gestation weeks. Ann Med 2013;45:446-54.

10. Kumar VS, Jeyaseelan L, Sebastian T, Regi A, Mathew J, Jose R. New birth weight reference standards customised to birth order and sex of babies from South India. BMC Pregnancy Childbirth 2013;13:38.

11. Itabashi K, Miura F, Uehara R, Nakamura Y. New Japanese neonatal anthropometric charts for gestational age at birth. Pediatr Int 2014;56:702-8.

12. Lim JS, Lim SW, Ahn JH, Song BS, Shim KS, Hwang IT. New Korean reference for birth weight by gestational age and sex: data from the Korean Statistical Information Service (2008-2012). Ann Pediatr Endocrinol Metab 2014;19:14653.

13. Beyer H, Tukey JW. Exploratory data analysis. S. Biom J 1981;23:413-4.

14. Barker DJ. Outcome of low birthweight. Horm Res 1994;42:223-30.

15. Albertsson-Wikland K, Karlberg J. Natural growth in children born small for gestational age with and without catch-up growth. Acta Paediatr Suppl 1994;399:64-70.

16. Sørensen HT, Sabroe S, Rothman KJ, Gillman M, Steffensen FH, Fischer P, et al. Birth weight and length as predictors for adult height. Am J Epidemiol 1999;149:726-9.
17. Eide MG, Øyen N, Skjaerven R, Nilsen ST, Bjerkedal T, Tell GS. Size at birth and gestational age as predictors of adult height and weight. Epidemiology 2005;16:175-81.

18. Clayton PE, Cianfarani S, Czernichow P, Johannsson G, Rapaport R, Rogol A. Management of the child born small for gestational age through to adulthood: a consensus statement of the International Societies of Pediatric Endocrinology and the Growth Hormone Research Society. J Clin Endocrinol Metab 2007;92:804-10.

19. Ranke MB, Lindberg A; KIGS International Board. Prediction models for short children born small for gestational age (SGA) covering the total growth phase. Analyses based on data from KIGS (Pfizer International Growth Database). BMC Med Inform Decis Mak 2011;11:38.

20. Ibáñez L, Lopez-Bermejo A, Díaz M, Jaramillo A, Marín S, de Zegher F. Growth hormone therapy in short children born small for gestational age: effects on abdominal fat partitioning and circulating follistatin and highmolecular-weight adiponectin. J Clin Endocrinol Metab 2010;95:2234-9.

21. Christensen T, Fidler C, Bentley A, Djurhuus C. The costeffectiveness of somatropin treatment for short children born small for gestational age (SGA) and children with growth hormone deficiency (GHD) in Sweden. J Med Econ 2010;13:168-78.

22. Wang X, Guyer B, Paige DM. Differences in gestational agespecific birthweight among Chinese, Japanese and white Americans. Int J Epidemiol 1994;23:119-28.

23. Shiono PH, Rauh VA, Park M, Lederman SA, Zuskar D. Ethnic differences in birthweight: the role of lifestyle and other factors. Am J Public Health 1997;87:787-93.

24. Madan A, Holland S, Humbert JE, Benitz WE. Racial differences in birth weight of term infants in a northern California population. J Perinatol 2002;22:230-5.

25. Shin SM, Chang YP, Lee ES, Lee YA, Son DW, Kim MH, et al. Low birth weight, very low birth weight rates and gestational age-specific birth weight distribution of Korean newborn infants. J Korean Med Sci 2005;20:182-7.

26. Kurtoğlu S, Hatipoğlu N, Mazıcıoğlu MM, Akın MA, Çoban D, Gökoğlu S, et al. Body weight, length and head circumference at birth in a cohort of Turkish newborns. J Clin Res Pediatr Endocrinol 2012;4:132-9.

27. Davidson S, Sokolover N, Erlich A, Litwin A, Linder N, Sirota L. New and improved Israeli reference of birth weight, birth length, and head circumference by gestational age: a hospital-based study. Isr Med Assoc J 2008;10:130-4.

28. Haksari EL, Lafeber HN, Hakimi M, Pawirohartono EP, Nyström L. Reference curves of birth weight, length, and head circumference for gestational ages in Yogyakarta, Indonesia. BMC Pediatr 2016;16:188.

29. Wilcox AJ. Birth weight, gestation, and the fetal growth curve. Am J Obstet Gynecol 1981;139:863-7. 